Arq. Bras. Med. Vet. Zootec., v.71, n.2, p.584-593, 2019

\title{
Perfil de resistência antimicrobiana de Klebsiella pneumoniae isoladas de animais domésticos e silvestres
}

\author{
[Antimicrobial resistance profile of Klebsiella pneumoniae isolated from domestic \\ and wild animals] \\ A.T.H.I. Sousa, H. Makino, V.C.M. Bruno, S.L. Candido, B.S. Nogueira, \\ I.G. Menezes, L. Nakazato, V. Dutra* \\ Universidade Federal de Mato Grosso - Cuiabá, MT
}

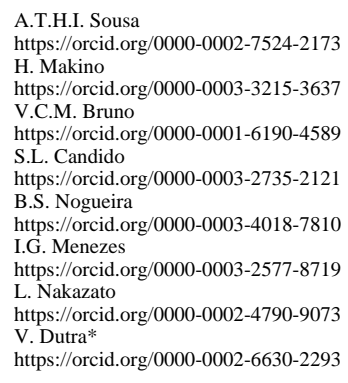

\section{RESUMO}

Klebsiella pneumoniae é um patógeno oportunista, responsável por diversos tipos de infecções nosocomiais, e é considerado um microrganismo multirresistente. Dados na literatura que forneçam informações a respeito da resistência desse microrganismo a antimicrobianos em amostras de animais são escassos. Dessa forma, o objetivo deste trabalho foi avaliar o perfil e o seu aumento das resistências a antimicrobianos dentro da medicina veterinária. Um total de 67 isolados de $K$. pneumoniae, provenientes de diferentes sítios de isolamento de animais domésticos (39/67) e silvestres (28/67), foi confirmado por sequenciamento do gene $16 \mathrm{~S}$ rRNA. O maior percentual de isolamento de $K$. pneumoniae foi de amostras de urina, com $16 \%$ (11/67), fezes, com $15 \%$ (10/67), e pulmão, com 13,5\% (09/67). No perfil de resistência, foram testadas 11 categorias de antibióticos, sendo a maior taxa de resistência ao metronidazol 97\% (65/67), à ampicilina 94\% (63/67), à amoxicilina 93\% (62/67), às sulfonamidas 93\% (62/67), à colistina 93\% (62/67) e à nitrofurantoína 88\% (59/67). Aqueles que apresentaram menor taxa de resistência foram: meropenem 3\% (2/67), imipenem 6\% (4/67) e amicacina $16 \%$ (11/67). Todos os isolados foram considerados bactérias multirresistentes (MRD), com o índice de resistência múltipla aos antibióticos (IRMA) variando de 0,15 a 0,85 e com 60 tipos de padrões de resistência. O resultado deste estudo reforça que os animais são reservatórios de $K$. pneumoniae multirresistentes.

Palavras-chave: Klebsiella pneumoniae, multirresistência, perfil de resistência, MRD

\begin{abstract}
Klebsiella pneumoniae is an opportunistic pathogen responsible for several types of nosocomial infections and is considered a multiresistant microorganism. Data in the literature that provide information regarding the resistance of this microorganism to antimicrobials in animal samples are scarce. Thus, the objective of this work was to evaluate the profile and its increase of antimicrobial resistance within Veterinary Medicine. A total of $67 \mathrm{~K}$. pneumoniae isolates from different domestic (39/67) and wild (28/67) isolation sites were confirmed by sequencing the 16S rRNA gene. The highest percentage of K. pneumoniae isolation was from urine samples with 16\% (11/67), faeces 15\% (10/67) and lung 13.5\% (09/67). In the resistance profile, 11 categories of antibiotics were tested, with the highest resistance to metronidazole being 97\% (65/67), ampicillin 94\% (63/67), amoxicillin 93\% (62/67), sulfonamides 93\% (62 / 67), 93\% colistin (62/67), and 88\% nitrofurantoin (59/67). The ones with the lowest resistance were: meropenem 3\% (2/67), imipenem 6\% (4/67) and amikacin 16\% (11/67). All isolates were considered multiresistant bacteria (MDR), with the Multiple Resistance to Antibiotics Index (IRMA) ranging from 0.15 to 0.85 and with 60 types of resistance patterns. The result of this study reinforces that the animals are reservoirs of multiresistant $\mathrm{K}$. pneumoniae.
\end{abstract}

Keywords: Klebsiella pneumoniae, multiresistance, resistance profile, MDR

Recebido em 20 de fevereiro de 2018

Aceito em 31 de agosto de 2018

* Autor para correspondência (corresponding author)

E-mail: valdutra@ufmt.br 


\section{INTRODUÇÃO}

As infecções clínicas por bactérias multirresistentes têm causado grande preocupação mundial, sendo consideradas um grave problema médico-social. Estão comumente associadas às falhas em terapias, ao aumento dos custos dos tratamentos e à morbidade e mortalidade de pacientes (Pereira et al., 2015).

Uma diversidade de patógenos pode estar relacionada à etiologia dessas infecções. Dentre as bactérias Gram-negativas, responsáveis por grande parte das infecções nosocomiais resistentes, a Klebisiela pneumoniae (K. pneumoniae), pertencente à família Enterobacteriaceae, destaca-se pela habilidade de desenvolver mecanismos de resistência enzimáticos e é considerada grande responsável por diferentes doenças infecciosas (Kolpa et al., 2018).

As doenças causadas por $K$. pneumoniae geralmente estão relacionadas com o estado imunológico do hospedeiro, e sua gravidade muitas vezes é potencializada devido à capacidade patogênica da cepa, capaz de criar um fenótipo de multirresistência ao uso exacerbado de antimicrobianos (Pereira et al., 2015).

Estudos de resistência de isolados de origem animal são escassos no Brasil. Dessa forma, o objetivo deste estudo foi investigar o perfil de susceptibilidade a antimicrobianos de $K$. pneumoniae isoladas de animais domésticos e silvestres.

\section{MATERIAL E MÉTODOS}

Todos os procedimentos adotados neste estudo foram aprovados pelo Comitê de Ética no Uso de Animais - Universidade Federal de Mato Grosso (Ceua-UFMT), sob o número de protocolo 23108.236834/2017-13.

Os isolados foram oriundos de materiais recebidos e processados, no período de 2016 e 2017, no Laboratório de Microbiologia do Hospital Veterinário da UFMT, de diferentes sítios de isolamento de animais domésticos e silvestres, sendo no total 67 isolados.
Os materiais foram semeados em ágar sangue ovino $8 \%$ (Sigma-Aldrich, Darmstadt, Alemanha), ágar MacConkey (Neogen Corporation, São Paulo, Brasil), em aerobiose, incubados a $37^{\circ} \mathrm{C}$ por até 72 horas, sendo feita a leitura das placas em 24, 48 e 72 horas. A identificação das colônias foi realizada de acordo com Quinn et al. (2013), por meio de morfologia, coloração de Gram, prova da catalase, teste de oxidase e série bioquímica (Triplo Sugar Iron - TSI, Sulfeto Indol Motilidade - SIM, Teste OF - GOF, citrato, manitol, inusitol e ureia) (Sigma-Aldrich, Darmstadt, Alemanha).

Após o isolamento, uma colônia de cada amostra foi inoculada em caldo infusão de cérebro e coração (BHI - Himedia Labs. Mumbai, Índia), incubada a $37^{\circ} \mathrm{C}$ overnight, e extraiu-se DNA genômico pelo método fenol-clorofórmio, de acordo com Sambrook e Russel (2004).

Os DNAs extraídos foram submetidos à PCR para o gene $16 \mathrm{~S}$ rRNA. A sequência de oligonucleotídeos utilizada foi 27F: AGA GTT TGA TCC TGG CTC AG (Lane, 1991) e 1492R: GGT TAC CTT GTT ACG ACT T (Turner et al., 1999), que amplifica um fragmento de 1512 pares de base (pb).

Cada reação foi composta de 10ng de DNA, 0,4 pmol de cada oligonucleotídeo, $0,2 \mathrm{mM}$ de deoxynucleoside triphosphates (dNTPs, SigmaAldriche, Alemanha), $3 \mathrm{mM}$ de $\mathrm{MgCl}_{2}$, 1x PCR buffer, $1 \mathrm{U}$ de taq DNA polimerase (Invitrogen by Thermo Fisher Scientific, Carlsbad, Califórnia, EUA) e água ultrapura q.s.p. para volume final de $25 \mu \mathrm{L}$. As reações foram amplificadas em um termociclador MyCycler ${ }^{\mathrm{TM}}$ (Biorad, Califórnia, EUA), com desnaturação inicial de cinco minutos a $95^{\circ} \mathrm{C}$, sucedido de 35 ciclos de desnaturação por 45 segundos a $95^{\circ} \mathrm{C}$, hibridização por um minuto a $52^{\circ} \mathrm{C}$ e um minuto e 30 segundos a $72^{\circ} \mathrm{C}$ de extensão, sendo concluída com um ciclo de extensão final a $72^{\circ} \mathrm{C}$ por sete minutos. Os produtos de PCR foram fracionados em gel de agarose $1,0 \%$, corado com GelRed $^{\mathrm{TM}}$ (Biotium ${ }^{\circledR}$, UK) a $10 \mathrm{~V} / \mathrm{cm}$, e visualizados em fotodocumentador.

Posteriormente, o produto obtido pela PCR foi purificado e sequenciado, no sequenciador automático ABI 3500 Genetic Analyzer (Applied Biosystems Foster, CA, EUA), de acordo com as 
recomendações do fabricante. As sequências foram comparadas e depositadas no banco de dados do GenBank, usando-se o BLAST no servidor NCBI (http:www.ncbi.nlm.nih.gov/ BLAST), pelo número de acesso 4325327, sendo selecionados os isolados que tiveram identidade de, no mínimo, 97\% com a K. pneumoniae, e foi utilizado o software DECIPHER para observação de quimeras; após isso, para a realização do teste de susceptibilidade.

O teste de susceptibilidade aos antimicrobianos foi realizado pelo método de difusão em disco, como descrito por Bauer et al. (1966), sendo testadas 11 categorias de antibióticos, como os $\beta$ lactâmicos (penicilinas, cefalosporinas e carbapenêmicos), aminoglicosídeo, quinolonas, fenicol, tetracíclicos, polimixina, nitroimidazol, nitrofuranos e sulfonamidas. Os discos testados foram: ampicilina $(10 \mu \mathrm{g}$, AMP), amoxicilina

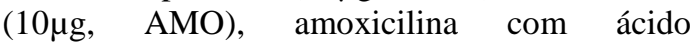
clavulanato $(30 \mu \mathrm{g}, \mathrm{AMC})$, amicacina $(30 \mu \mathrm{g}$, AMI), gentamicina $(10 \mu \mathrm{g}, \mathrm{GEN})$, neomicina $(30 \mu \mathrm{g}, \mathrm{NEO})$, cefalexina $(30 \mu \mathrm{g}, \mathrm{CFE})$, ceftiofur $(30 \mu \mathrm{g}, \mathrm{CTF})$, enrofloxacina $(5 \mu \mathrm{g}, \mathrm{ENO})$, ciprofloxacina $(5 \mu \mathrm{g}, \mathrm{CIP})$, marbofloxacina $(5 \mu \mathrm{g}$, MBF), imipinem (10 $\mu \mathrm{g}, \quad$ IPM),

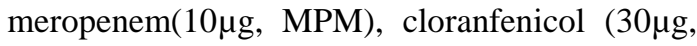
CLO), doxiciclina $(30 \mu \mathrm{g}, \mathrm{DOX})$, colistina $(10 \mu \mathrm{g}$,

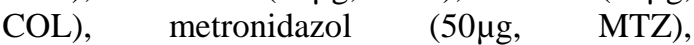
nitrofurantoína $(300 \mu \mathrm{g}, \quad \mathrm{NIT}), \quad$ sulfonamidas $(300 \mu \mathrm{g}, \mathrm{SUL})$ e sulfonamidas com trimetoprim $(25 \mu \mathrm{g}, \mathrm{SUT})$. Foram classificados de acordo com os critérios do Clinical and Laboratory Standards Institute - CLSI (Performance..., 2016), sendo aqueles que se apresentaram como parcialmente sensíveis e resistentes agrupados como resistentes.

Os isolados foram classificados quanto ao perfil de resistência como descrito por Magiorakos et al. (2012), em que é definida como bactéria multirresistente a drogas (MRD) quando possui resistência a um ou mais agentes em três ou mais categorias de antimicrobianos.
Para cada isolado, o índice de resistência múltipla aos antibióticos (IRMA) foi calculado pela seguinte fórmula: IRMA= número de antibióticos para os quais a amostra foi resistente $\div$ número total de antibióticos testados. Se o valor der maior ou igual a 0,2, indica uma resistência múltipla (Krumperman, 1983).

\section{RESULTADOS}

No total, foram 75 isolados com características morfológicas e bioquímicas parecidas com o gênero Klebsiella; destas, foram confirmadas 67 amostras como $K$. pneumoniae, cinco amostras como $K$. oxytoca (duas aves silvestres, um canino, um bovino, uma onça-parda) e uma amostra como $K$. variicola (um cachorro-domato) pelo seqüenciamento; dentro da espécie $K$. pneumoniae, houve uma maior frequência em animais domésticos, com 58\% (39/67), do que em animais silvestres, com 42\% (28/67), sendo destes 19 de vida livre ( 15 aves e três mamíferos e um réptil ) e nove de cativeiro (Tab. 1).

Os isolados foram obtidos de 21 sítios diferentes de isolamento, sendo os mais frequentes as amostras de urina $16 \%(11 / 67)$, fezes $15 \%$ (10/67) e pulmão $13,5 \%$ (09/67), como pode ser observado na Tab. 2.

No teste de disco-difusão em ágar, foram observados altos percentuais de susceptibilidade aos antimicrobianos testados de acordo com os critérios do CLSI (Performance..., 2016). Em animais domésticos e silvestres, foi observada alta resistência a metronidazol 97\% (65/67), ampicilina 94\% (63/67), amoxicilina 93\% (62/67), sulfonamidas 93\% (62/67), colistina $93 \%$ (62/67) e nitrofurantoína 88\% (59/67). Aqueles que apresentaram menor taxa de resistência foram: meropenem 3\% (2/67), imipenem $6 \%(4 / 67)$ e amicacina $16 \%(11 / 67)$ (Tab. 3). Todos os isolados foram classificados como MRD, conforme pode ser observado na Tab. 4. 
Tabela 1. Relação do número de isolados de Klebsiella pneumoniae com os animais hospedeiros divididos em domésticos e silvestres - Cuiabá - 2017

\begin{tabular}{lccc}
\hline & Hospedeiro & Hospedeiro & Total \\
\hline \multirow{4}{*}{ (Nome popular) } & (Nome científico) & 16 \\
$(\mathrm{n}=39)$ & Canina & Canis lupus familiaris & 8 \\
& Equina & Equus caballus & 7 \\
& Bovina & Bos taurus & 5 \\
& Felina & Felis catus & 2 \\
& Suína & Sus scrofa domesticus & 1 \\
& Roedor & Rattus norvegicus & 2 \\
& Tucano-toco & Ramphastos toco & 1 \\
& Gavião-caboclo & Buteogallus meridionalis & 3 \\
& Arara-canindé & Ara ararauna & 1 \\
& Roselha-do-leste & Platycercus euimius & 6 \\
Silvestres & Arara-azul & Anodorhynchus hyacinthinus & 2 \\
$(\mathrm{n}=28)$ & Urutau & Nyctibius griseus & 1 \\
& Pato-do-mato & Cairina moschata & 1 \\
& Papagaio-verdadeiro & Amazona aestiva & 1 \\
& Socó & Tigrisoma lineatum & 1 \\
& Jibóia-constritora & Boa constrictor & 1 \\
& Jacaré & Caiman yacare & 1 \\
& Onça-parda & Puma concolor & 1 \\
& Macaco-prego & Sapajus apella & 2 \\
& Cachorro-do-mato & Cerdocyon thous & 2 \\
& Quati & Nasua nasua & 1 \\
& Tamanduá-bandeira & Myrmecophaga tridactyla & 1 \\
\hline
\end{tabular}

Tabela 2. Frequência absoluta e porcentagem de sítio de isolamento das 67 amostras de K. pneumoniae em um Hospital Veterinário, Mato Grosso

\begin{tabular}{lcc}
\multicolumn{1}{c}{ Sítios/amostras } & Frequência absoluta & Percentual \\
\hline Urina & 11 & $16 \%$ \\
Fezes & 10 & $15 \%$ \\
Pulmão & 09 & $13,5 \%$ \\
Suabe otológico & 5 & $7,5 \%$ \\
Cavidade oral & 4 & $6 \%$ \\
Suabe ocular & 4 & $6 \%$ \\
Fígado & 3 & $4,5 \%$ \\
Lesão de membro & 3 & $4,5 \%$ \\
Saco aéreo & 3 & $4,5 \%$ \\
Pele & 3 & $4,5 \%$ \\
Lavado traqueobrônquico & 2 & $3 \%$ \\
Coração & 1 & $1,5 \%$ \\
Encéfalo & 1 & $1,5 \%$ \\
Inglúvio & 1 & $1,5 \%$ \\
Leite & 1 & $1,5 \%$ \\
Líquido articular & 1 & $1,5 \%$ \\
Liquido torácico & 1 & $1,5 \%$ \\
Líquido abdominal & 1 & $1,5 \%$ \\
Suabe de cloaca & 1 & $1,5 \%$ \\
Suabe nasal & 1 & $1,5 \%$ \\
Placenta & 1 & $1,5 \%$ \\
& 67 & $100 \%$ \\
\hline
\end{tabular}


Tabela 3. Perfil de resistência aos antimicrobianos dos isolados de K. pneumoniae por meio de discodifusão em ágar

\begin{tabular}{lcccc}
\hline \multicolumn{1}{c}{\begin{tabular}{c} 
Antimicrobianos \\
\multicolumn{1}{c}{ Categorias }
\end{tabular}} & Agente & $\begin{array}{c}\text { Resistência* }(\%) \\
\text { Domicos }(\mathrm{n}=\end{array}$ & $\begin{array}{c}\text { Silvestres } \\
(\mathrm{n}=28)\end{array}$ & $\begin{array}{c}\text { Total } \\
(\mathrm{n}=67)\end{array}$ \\
\hline Penicilinas & AMO & $92 \%(36)$ & $93 \%(26 / 28)$ & $93 \%(62 / 67)$ \\
$\beta$ - lactâmicos & AMC & $44 \%(17 / 39)$ & $50 \%(14 / 28)$ & $46 \%(31 / 67)$ \\
Cefalosporinas & AMP & $92 \%(36 / 39)$ & $96 \%(27 / 28)$ & $94 \%(63 / 67)$ \\
$\beta-$ lactâmicos & CFE & $44 \%(17 / 39)$ & $64 \%(18 / 28)$ & $51 \%(34 / 67)$ \\
Carbapenêmicos & CTF & $49 \%(19 / 39)$ & $61 \%(17 / 28)$ & $51 \%(34 / 67)$ \\
$\beta-$ lactâmicos & MPM & $5 \%(2 / 39)$ & $0 \%(0 / 28)$ & $3 \%(2 / 67)$ \\
& IPM & $3 \%(1 / 39)$ & $11 \%(3 / 28)$ & $6 \%(4 / 67)$ \\
Aminoglicosídeos & AMI & $20 \%(7 / 39)$ & $14 \%(4 / 28)$ & $16 \%(11 / 67)$ \\
& GEN & $38 \%(15 / 39)$ & $36 \%(10 / 28)$ & $37 \%(25 / 67)$ \\
Quinolonas & NEO & $69 \%(27 / 39)$ & $75 \%(21 / 28)$ & $72 \%(48 / 67)$ \\
& ENO & $62 \%(24 / 39)$ & $75 \%(21 / 28)$ & $67 \%(45 / 67)$ \\
Fenicol & CIP & $49 \%(19 / 39)$ & $46 \%(13 / 28)$ & $48 \%(32 / 67)$ \\
Polimixina & MBF & $54 \%(21 / 39)$ & $61 \%(17 / 28)$ & $57 \%(38 / 67)$ \\
Tetracíclicos & CLO & $51 \%(20 / 39)$ & $68 \%(19 / 28)$ & $58 \%(39 / 67)$ \\
Nitroimidazol & COL & $87 \%(34 / 39)$ & $93 \%(26 / 28)$ & $93 \%(62 / 67)$ \\
Nitrofuranos & DOX & $44 \%(17 / 39)$ & $79 \%(22 / 28)$ & $43 \%(29 / 67)$ \\
Sulfonamidas & MTZ & $95 \%(37 / 39)$ & $100 \%(28 / 28)$ & $97 \%(65 / 67)$ \\
& NIT & $82 \%(32 / 39)$ & $96 \%(27 / 28)$ & $88 \%(59 / 67)$ \\
\hline & SUL & $97 \%(38 / 39)$ & $96 \%(27 / 28)$ & $93 \%(62 / 67)$ \\
& SUT & $44 \%(17 / 39)$ & $36 \%(10 / 28)$ & $40 \%(27 / 67)$ \\
\hline
\end{tabular}

Legenda: AMO: amoxicilina, AMC: amoxicilina + ácido clavulânico, AMP: ampicilina, CFE; cefalexina, CTF: ceftiofur, MPM: meropenem, IPM: imipenem, AMI: amicacina, GEN: gentamicina, NEO: neomicina, ENO: enrofloxacina, CIP: ciprofloxacina, MBF: marbofloxacina, CLO: cloranfenicol, COL: colistina - polimixina E, DOX: doxiciclina, MTZ: metronidazol, NIT: nitrofurantoína, SUL: sulfonamidas, SUT: sulfonamida+trimetoprima *Amostras classificadas como intermediárias foram agrupadas com aquelas classificadas como resistentes. Em destaque, os valores que apresentaram maiores e menores perfis de resistências.

Tabela 4. Distribuição da frequência de resistência a classes de drogas dos 67 isolados de K. pneumoniae de afecções clínicas no Hospital Veterinário

\begin{tabular}{lccc}
\hline Categorias & $\begin{array}{c}\text { Domésticos } \\
(\mathrm{n}=39)\end{array}$ & $\begin{array}{c}\text { Silvestres } \\
(\mathrm{n}=28)\end{array}$ & $\begin{array}{c}\text { Total } \\
(\mathrm{n}=67)\end{array}$ \\
\hline 3 & $10 \%(4 / 39)$ & $0 \%(0 / 28)$ & $6 \%(4 / 67)$ \\
4 & $10 \%(4 / 39)$ & $0 \%(0 / 28)$ & $6 \%(4 / 67)$ \\
5 & $0 \%(0 / 39)$ & $4 \%(1 / 28)$ & $1 \%(1 / 67)$ \\
6 & $3 \%(1 / 39)$ & $4 \%(1 / 28)$ & $3 \%(2 / 67)$ \\
7 & $15 \%(6 / 39)$ & $11 \%(3 / 28)$ & $14 \%(9 / 67)$ \\
8 & $15 \%(6 / 39)$ & $21 \%(6 / 28)$ & $18 \%(12 / 67)$ \\
9 & $26 \%(10 / 39)$ & $25 \%(7 / 28)$ & $25 \%(17 / 67)$ \\
10 & $15 \%(6 / 39)$ & $36 \%(9 / 28)$ & $22 \%(15 / 67)$ \\
11 & $5 \%(2 / 39)$ & $4 \%(1 / 28)$ & $4 \%(3 / 67)$ \\
\hline
\end{tabular}

Em relação ao IRMA, 97\% (65/67) apresentaram múltipla resistência; o índice variou entre $0,15 \mathrm{e}$ 0,85 , sendo a média de IRMA dos isolados estudados de 0,57. No total, foram 60 tipos de padrões de resistência, sendo o mais comum o AMC-AMO-AMP-CFE-CTF-GEN-NEO-ENOCIP-MBF-CLO-COL-DOS-MTZ-NIT-SULSUT $(7,5 \%, 5 / 67)$, em seguida o AMO-AMP-
COL-MTZ-NIT $(4,5 \%, 3 / 67)$ e o AMO-AMPCTF-NEO-ENO-CLO-COL-MTZ-NIT-SUL $(3 \%, 2 / 67)$.

\section{DISCUSSÃO}

Um dos maiores problemas na saúde pública é o aumento de cepas multirresistentes a 
antimicrobianos e, entre as bactérias pertencentes a esse grupo, está a K. pneumoniae. A ocorrência de $K$. pneumoniae neste estudo foi maior em animais domésticos, sobretudo cães e equinos, provavelmente devido ao maior número de amostras recebidas, no entanto foi observada alta frequência de isolados de aves silvestres tanto de vida livre quanto de cativeiro, provavelmente por pertencerem a microbiota desses animais, como foi observado em um estudo envolvendo gaviões carijós, em que foi coletado suabe cloacal de nove animais saudáveis e identificou-se a $K$. pneumoniae (Araújo Silva et al., 2016). Mas foi relatado também que esses microrganismos podem estar envolvidos em processos mórbidos em aves, como causadores de enterites e problemas respiratórios, podendo levar a óbitos (Melville et al., 2004).

Esse gênero está presente no meio ambiente, sendo encontrado em corpos hídricos, esgoto, solo, vegetação, mucosas, sobretudo do trato gastrointestinal de animais e humanos. As principais infecções causadas por essas bactérias multirresistentes são urinárias, pulmonares e enterites. O resultado foi compatível aos encontrados na literatura (Pereira et al., 2015).

Observou-se, em animais domésticos e silvestres, o aumento de resistência antimicrobiana em isolados de $K$. pneumoniae, principalmente aos $\beta$-lactâmicos, como a amoxicilina e a ampicilina, pois possuem capacidade de produzir enzimas hidrolíticas que inativam os antimicrobianos dessa classe, sendo um dos mecanismos de resistência bacteriana mais importante (Ogalo et al., 2016). No entanto, dentro desse mesmo grupo, quando se utilizou a associação de penicilina com inibidor da $\beta$-lactamase, foi encontrada uma diminuição na resistência.

O antibiótico que apresentou a maior taxa de resistência foi o metronidazol, um dos principais antimicrobianos utilizados na rotina médica veterinária, sobretudo em animais de companhia, em razão de sua excelente atividade contra microrganismos anaeróbico e protozoários. Com sua ampla utilização, pode ter levado à aquisição de mecanismos de resistência contra esse fármaco (Dechan, 1997). Nos isolados de $K$. pneumoniae de humanos, não apresentam tanta resistência por não serem utilizados corriqueiramente na rotina médica (Nakano et al., 2011).
O percentual de resistência encontrado em relação às sulfonamidas e sulfonamida+trimetoprima foi de $93 \%$ e $40 \%$, respectivamente, nas amostras do presente estudo. Essa resistência à sulfonamida encontrase amplamente disseminada em bactérias isoladas de animais, refletindo o uso indiscriminado dessas drogas ao longo de anos como melhoradores de desempenho animal, controle de infeções e tratamento. Isso limitou muito a eficácia desse fármaco no tratamento de doenças bacterianas de animais, assim são poucas as indicações para uso primário (Bezerra et al., 2017). Com a associação da sulfa com trimetoprina, ocorre a inibição do ácido fólico das bactérias, com isso houve uma diminuição na taxa de resistência nos isolados.

A polimixina, principalmente a $\mathrm{E}$ (colistina), foi muito utilizada na rotina de melhoradores de desempenho em animais de produção, como aditivo das composições na ração para aves, bovino e suíno, tendo hoje o seu uso proibido para animais de produção (Brasil, 2017). Esse deve ser um dos motivos por ter apresentado alta taxa de resistência nos isolados de animais. Atualmente, na medicina humana, as polimixinas B e E são utilizadas como opção terapêutica em infecções causadas por bactérias multirresistentes, principalmente as Gram negativas. Apesar de as taxas de resistência às polimixinas serem consideradas baixas na medicina humana, já existem relatos de resistência a esses antibióticos, principalmente a colistina, em isolados de $K$. pneumoniae (Jeannot et al., 2017; Hernandez et al., 2018).

Outro antibiótico também muito empregado como aditivo melhorador de desempenho animal foi o fármaco nitrofurantoína. Nos isolados de animais silvestres (96\%) e domésticos (82\%), foram observadas altas taxas de resistência, mesmo em animais silvestres de vida livre que nunca tinham sido medicados. Isso deve ter acontecido pela contaminação ambiental e pela aquisição de resistência pelas bactérias a esse fármaco (Bezerra et al., 2017). Em contrapartida, na medicina humana, esse antimicrobiano voltou a ser utilizado, por ser bactericida de amplo espectro. Com o aumento contínuo da resistência aos antibióticos em bactérias Gram negativas produtoras de $\beta$-lactamases de espectro estendido (ESBL) e a disponibilidade limitada de novos antibióticos, o uso da nitrofurantoína tem sido 
reavaliado, principalmente para o tratamento de infecções do trato urinário, e tem apresentado eficiência contra a maioria dos isolados de $K$. pneumoniae (Seifu e Gebissa, 2018).

Dentro dos aminoglicosídeos, a amicacina apresentou menor taxa de resistência e é a que tem menor potencial para induzir a resistência bacteriana, pois a $K$. pneumoniae possui pouca detecção do gene metilase, o principal mecanismo de resistência a esse fármaco. Por isso, são muito utilizados para o tratamento de infecções nosocomiais (Jajić et al., 2017; Zheng et al., 2018).

Os carbapenêmicos apresentaram baixa taxa de resistência, pois essa classe ainda é pouco utilizada na medicina veterinária. São utilizados em animais de companhia, em infecções graves (Monteani-Ferreira et al., 1999). Já os isolados de humanos têm apresentado alta taxa de resistência pela presença enzima carbapenemase (KPC), como descrito pelos autores (Pereira et al., 2015; Jajić et al., 2017).

Neste estudo, foi observado que todos os isolados apresentaram multirresistência, sendo classificados como MRD. Existem outros relatos na literatura em que foi observada essa multirresistência a esse patógeno (Jeannot et al., 2017; Hernández et al., 2018). Em um estudo realizado por Kolpa e colaboradores (2018), foi analisado $o$ perfil de susceptibilidade a antimicrobianos em uma Unidade de Tratamento Intensivo (UTI) humana no sul da Polônia, onde foram estudados 510 isolados de pacientes de diversos quadros clínicos, como pneumonia, infecção sanguínea, infecção do trato urinário, enterites, infecção no local cirúrgico, infecção da pele e tecidos moles, e outras infecções. Dos 35 isolados de $K$. pneumoniae, $42 \%$ foram classificados como MRD. Portanto, deve ocorrer o monitoramento da resistência aos medicamentos das cepas multirresistentes.

O aumento de cepas multirresistentes de $K$. pneumoniae tem sido um grande problema tanto na medicina veterinária quanto na medicina humana. Esse microrganismo é capaz de provocar resistência de até $95 \%$ dos antimicrobianos existentes no mercado farmacêutico, pois produz uma enzima que confere resistência a diversas classes de antibióticos, tornando, assim, as opções de tratamentos muito restritas (Pereira et al., 2015). Pode ser observado, no presente trabalho, que existem cepas que foram resistentes a todas as categorias de antibióticos testados. No IRMA, 97\% dos isolados foram classificados como bactérias de resistência múltipla e os padrões de resistência variaram muito, sendo resistentes principalmente aqueles que são mais utilizados na linha veterinária. Esse resultado é considerado um problema de saúde pública, pois infecções causadas por microrganismos multirresistentes, na maioria das vezes, não respondem à terapia convencional, e isso prolonga a duração da doença, podendo levar a óbito.

Existem muitos estudos descrevendo que o uso de antibióticos na medicina veterinária proporciona uma transferência de resistência para as bactérias emergentes humanas, pois muitas classes desses fármacos que são usadas em animais também são empregadas em seres humanos. Vários questionamentos têm sido feitos em relação ao risco para a saúde pública pelo uso exacerbado de fármacos na produção animal e na agricultura (Arias e De Maio Carrilho, 2012).

De acordo com Gandolfi-Decristophorus et al. (2013), existe essa associação e já foi relatada a transferência de material genético entre espécies, por apresentar similaridades genéticas entre espécies, por apresentar similaridades genéticas entre os isolados de humanos e animais. Porém, Phillips et al. (2004) afirmam que a maior causa de resistência em medicina humana advém de tratamento malconduzido, que a influência de terapias em animais é mínima e as bactérias isoladas de animais não persistem em seres humanos. Mesmo com a eliminação do uso de antimicrobianos em animais, isso não reduzirá a multirresistência das bactérias na medicina humana se o uso de forma imprudente continuar nas terapias.

Foi realizado um estudo, em vários países da União Europeia, relacionado à susceptibilidade antimicrobiana de isolados intestinais de Escherichia coli, Salmonella spp., Campylobacter spp. e Enterococcus spp. de frangos, suínos e bovinos e constatou-se uma variação na resistência entre antimicrobianos, bactérias, hospedeiros e países. Observou-se uma baixa ou ausência de resistência em isolados de Escherichia coli, Campylobacter spp., 
Enterococcus spp. e Salmonella spp. a novos antimicrobianos usados em humanos, restritos a uso hospitalar, enquanto a resistência aos antimicrobianos mais utilizados na medicina veterinária e mais antigos, como ampicilina, tetraciclina e sulfametoxazol-trimetoprima, apresentou-se alta. Concluiu-se que os antimicrobianos utilizados somente na medicina humana apresentaram baixa ou nula taxa de resistência (De Jong et al., 2009), como foi observado no presente estudo.

Um dos problemas na atualidade é o uso e a prevalência ambiental de produtos farmacêuticos ativos, que são detectados em todo meio ambiente, como água, solo, sedimentos, esgotos e lamas (Lees et al., 2016). A presença de antibióticos no meio ambiente é uma preocupação séria por poder levar ao surgimento de resistência. De acordo com o Martinez et al. (2004), as atividades comerciais e o transporte entre países podem ocasionar a presença de bactérias resistentes em populações humanas e animais, incluindo espécies silvestres e aves que não receberam antimicrobianos. Pode ser observada altas taxas de resistência mesmo em animais silvestres de vida livre que não haviam sido medicados, os quais provavelmente adquiriram essas bactérias multirresistentes pela contaminação ambiental (Jechalke et al., 2014).

São vários os fatores que contribuíram para o aumento dessa resistência, como o uso abusivo de antimicrobianos em seres humanos e animais, a eliminação incorreta dos medicamentos e o tratamento inadequado de esgoto. Para tentar minimizar o problema, os profissionais da saúde, os produtores, as autoridades de saúde e as companhias farmacêuticas devem implementar medidas adequadas que diminuam a transmissão da resistência, levando em consideração a epidemiologia das bactérias, a interação entre seres humanos e animais, o uso correto de antimicrobianos em todas as espécies, a aplicação de princípios gerais de controle de infecção, as práticas modernas de criação e abate de animais, a manipulação e o preparo adequado dos alimento (Arias e De Maio Carrilho, 2012).
Os resultados do presente estudo reforçam a importância do monitoramento constante do perfil de resistência bacteriana, da identificação bacteriana e da realização do antibiograma como parâmetro para tratamento eficiente, visto que o tratamento empírico pode levar à aquisição de resistência antimicrobiana.

\section{CONCLUSÕES}

A $K$. pneumoniae se torna cada vez mais uma ameaça à saúde pública, pela alta taxa de resistência a antimicrobianos observada nos isolados de animais domésticos e silvestres. Neste estudo, evidenciou-se a ocorrência de isolados MRD com alta resistência a metronidazol, ampicilina, amoxicilina, sulfonamidas, colistina e nitrofurantoína em isolados de animais domésticos e silvestres. Esses animais podem ser uma fonte de isolados resistentes aos principais antimicrobianos utilizados em medicina humana. São necessárias medidas de controle da disseminação de resistência, sendo uma das formas para diminuir o uso indiscriminado dos antibióticos a realização de cultura e antibiograma para tratamento mais eficaz, com administração em doses corretas por tempo adequado.

\section{REFERÊNCIAS}

ARAÚJO SILVA, E.F.; BARROS, J.F.S.; FRAGA, K.B. et al. Enterobacterias isoladas da cloaca de Gaviões-carijós (Rupornis magnirostris, GMELIN, 1788) cativos e seu perfil de susceptibilidade a antimicrobianos. Braz. J. Vet. Res. Anim. Sci., v.53, p.207-213, 2016.

ARIAS, M.V.B.; DE MAIO CARRILHO, C.M.D. Antimicrobial resistance in animals and in human being. There is reason for concern? Semin. Ciênc. Agrár., v.33, p.775-790, 2012.

BAUER, A.W.; KIRBY, W.M.M.; SHERRIS, J.C. et al. Antibiotic susceptibility testing by a standardized single disk method. Am. J. Clin. Pathol., v.45, p.493, 1966.

BEZERRA, W.G.A.; HORN, R.H.; SILVA, I.N.G. et al. Antibióticos no setor avícola: uma revisão sobre a resistência microbiana. Arch. Zootec., v.66, p.301-307, 2017. 
BRASIL. Ministério da Agricultura. Secretaria de Inspeção de Produto Animal. Programa de prevenção e controle de antimicrobianos. Substâncias proibidas na alimentação animal com a finalidade de aditivos e legislação correspondente. 2017. Disponível em: http://www.agricultura.gov.br/noticias/ministerio -da-agricultura-cria-programa-de-prevencao-econtrole-de-antimicrobianos. Acessado em: 20 jan. 2018.

DE JONG, A.; BYWATER, R.; BUTTY, P. et al. A pan-Europeian survey of antimicrobial susceptibility towards human-use antimicrobial drugs among zoonotic and commensal enteric bacteria isolated from healthy food-producing animals. J. Antimicrobial Chemother., v.63, p.733-744, 2009.

DECHAN, J. Combination of medical and surgical therapy for pleuropneumonia in a horse. Can. Vet. J., v. 38, p.499, 1997.

GANDOLFI-DECRISTOPHORIS, P.; PETRINI, O.; RUGGERI-BERNARDI, N. et al. Extendedspectrum $\quad \beta$-lactamase-producing Enterobacteriaceae in healthy companion animals living in nursing homes and in the community. Am. J. Infect. Control, v.41, p.831$835,2013$.

HERNÁNDEZ, M.; QUIJADA, N.M.; LORENTE, L.L.U. et al. Infrequent isolation of extensively drug-resistant (XDR) Klebsiella pneumoniae resistant to colistin in Spain. Int. J. Antimicrobial Agents, v.51, p.531-533, 2018.

JAJIĆ, I.; BENČIĆ, A.; SIROGLAVIĆ, M. et al. Klebsiella pneumoniae oxa-48 in a urology patient: case report. Acta Clin. Croatica, v.56, p.166-171, 2017.

JEANNOT, K.; BOLARD, A.; PLÉSIAT, P. Resistance to polymyxins in Gram-negative organisms. Int. J. Antimicrobial Agents, v.49, p.526-535, 2017.

JECHALKE, S.; HEUER, H.; SIEMENS, J. et al. Fate and effects of veterinary antibiotics in soil. Trends Microbiol., v.22, p.536-545, 2014.

KOŁPA, M.; WAŁASZEK, M.; GNIADEK, A. et al. Incidence, microbiological profile and risk factors of healthcare-associated infections in intensive care units: a 10 year observation in a Provincial Hospital in Southern Poland. Int. J. Environ. Res. Public Health, v.15, p.112, 2018.
KRUMPERMAN, P.H. Multiple antibiotic resistance indexing of Escherichia coli to identify high-risk sources of fecal contamination of foods. Appl. Environ. Microbiol, v.46, p.165170,1983

LANE, D.J. 16S/23S rRNA sequencing. Nucleic acid techniques in bacterial systematics. New York: John Wiley \& Sons, 1991. p.125-175.

LEES, K.; FITZSIMONS, M.; SNAPE, J. et al. Pharmaceuticals in soils of lower income countries: physico-chemical fate and risks from wastewater irrigation. Environ. Int., v.94, p.712723, 2016.

MAGIORAKOS, A.P.; SRINIVASAN, A.; CAREY, R.B. et al. Multidrug-resistant, extensively drug-resistant and pandrug-resistant bacteria: an international expert proposal for interim standard definitions for acquired resistance. Clin. Microbiol. Infect., v.18, p.268$281,2012$.

MARTÍNEZ, J.; MARTÍNEZ, L. How are gene sequence analyses modifying bacterial taxonomy? The case of Klebsiella. Int. Microbiol., v.7, p.261-268, 2004.

MELVILLE, P.A.; COGLIATI, B.; MANGIATERRA, M.B.B.C.D. et al. Determinação da microbiota presente na cloaca e orofaringe de avestruzes (Struthio camelus) clinicamente sadios. Ciênc. Rural, v.34, p.18711876, 2004.

MONTEANI-FERREIRA，F.; WARTH， J.F.; PACHALY, J.R. et al. Contribuição ao estudo da ação da meropenema, in vitro e in vivo, em infecções diagnosticadas em pequenos animais. Arq. Ciênc. Vet. Zool. UNIPAR, v.2, p.131-134, 1999.

NAKANO, V.; SILVA, A.N.; MERINO, V.R.C. et al. Antimicrobial resistance and prevalence of resistance genes in intestinal Bacteroidales strains. Clinics, v.66, p.543-547, 2011.

OGALO, E.A.; OWUOR, C.O.; BOOR, K.G. et al. High prevalence of multi-drug resistant Klebsiella pneumoniae in a tertiary teaching hospital in western Kenya. Afr. J. Infect. Dis., v.10, p.89-95, 2016. 
PEREIRA, P.S.; BORGHI, M.; ARAÚJO, C.F. et al. Clonal dissemination of OXA-370producing Klebsiella pneumoniae in Rio de Janeiro, Brazil. Antimicrobial Agents Chemother., v.59, p.4453-4456, 2015.

PERFORMANCE standards for antimicrobial susceptibility testing. Document M100-S26. Informational supplement. 26.ed. Wayne, PA: Clinical and Laboratory Standards Institute, 2016.

PHILLIPS, I.; CASEWELL, M.; COX, T. et al. Does the use of antibiotics in food animals pose a risk to human health? A critical review of published data. J. Antimicrobial Chemother., v.53, p.28-52, 2004.

QUINN, P.J.; CARTER, M.E.; MARKEY, B.K. et al. General procedures in microbiology. Clinical veterinary microbiology. 2.ed. St Louis: Mosby, 2013. 920p.
SAMBROOK, J.; RUSSEL, D.W. Molecular cloning: a laboratory manual. 3.ed. New York: Cold Spring Harbor Laboratory Press, 2004. p.5.65-5.67.

SEIFU, W.D.; GEBISSA, A.D. Prevalence and antibiotic susceptibility of Uropathogens from cases of urinary tract infections (UTI) in Shashemene referral hospital, Ethiopia. BMC Infect. Dis., v.18, p.30, 2018.

TURNER, S.; PRYER, K.M.; MIAO, V.P.W. et al. Investigating deep phylogenetic relationships among cyanobacteria and plastids by small subunit rRNA sequence analysis. J. Eukaryotic Microbiol., v.46, p.327-338, 1999.

ZHENG, S.H.; CAO, S.J.; XU, H. et al. Risk factors, outcomes and genotypes of carbapenemnonsusceptible Klebsiella pneumoniae bloodstream infection: a three-year retrospective study in a large tertiary hospital in Northern China. Infect. Dis., v.50, p.443-451, 2018. 